\title{
Aplicación e impacto de la Ley de Habitaciones Obreras de 1906: el caso de Valparaíso (Chile)
}

Pablo Millán-Millán. Pontificia Universidad Católica de Valparaíso, Chile.

RESUMEN | El tema de las habitaciones para obreros fue una cuestión que afectó generalizadamente a las grandes ciudades, sobre todo a finales del siglo XIX. Chile fue uno de los países precursores en abordar esta problemática, con la formulación de un novedoso aparato legislativo ad hoc. La Ley de Habitaciones Obreras de 1906 enfrentó esta situación intentando plantear soluciones a un conflicto que se hacía cada vez más acuciante -el de las necesidades de vivienda de las crecientes masas obreras- sin embargo, su impacto en la sociedad no se dio de forma homogénea. En el caso de Valparaíso, la ubicación geográfica singular de la ciudad, sus limitadas posibilidades de desarrollo espacial y el contexto de precariedad social y material de su población, constituyeron obstáculos para el logro de los resultados esperados de dicha ley. En este artículo se analizan sus impactos en algunos aspectos urbanos y territoriales de la ciudad porteña, que acabaron configurando un modelo urbano híbrido y exclusivo que ha pervivido hasta nuestros días.

PALABRAS ClAVE | vivienda, política habitacional, estructura urbana.

ABSTRACT | The issue of workers' housing affected most big cities in the world, chiefly at the end of the XIX century. Chile was one of the pioneer countries in enacting a law system built to confront the core of the problem. The 1906 Workers' Housing Law dealt with a new situation - the growing needs of blue-collar workers regarding housing - trying to implement solutions to an ever more pressing problem, although it did not affect all of society in a similar way. In the case of Valparaiso, its particular geographical location, limited possibilities of spatial development and a context of material and social needs prevented this Law to achieve its expected results. This paper analyses the Law's impact on some of Valparaiso's territorial and urban aspects, leading to the configuration of a hybrid and exclusive urban model which has so far survived.

KEY WORDs | housing, housing policy, urban structure. 


\section{Introducción}

El final del siglo xIx muestra en Valparaíso un contexto en el que la pobreza y la necesidad de vivienda se dejaron sentir de manera acuciante, como en muchas otras grandes ciudades que crecían a un ritmo vertiginoso. Agudizada esta situación por las malas condiciones de vida de los grupos populares, que se iban incrementando con las numerosas migraciones campo-ciudad tras mejores condiciones laborales, se fueron buscando soluciones parciales, sobre todo tras sufrir la ciudad alguna catástrofe, como inundaciones o terremotos (De Ramón, 1990, p. 6).

Tal situación no era privativa de Valparaíso, sino vigente en todas las grandes ciudades del mundo occidental. Y en todas ellas, conforme se agudizaba la "cuestión social" -que tuvo en la problemática de la vivienda parte de su origen-, fue haciéndose más patente para los grupos sociales más reivindicativos la precaria situación habitacional de los sectores obreros. Se hizo evidente con ello la necesidad de una legislación que se hiciera cargo de las carencias en ese ámbito, demanda que acabó materializándose en el Congreso Internacional de Casas Baratas de París, de 1889. De estos encuentros surgirían las nuevas políticas habitacionales que fueron adoptando diferentes países (Capel, 2002, p. 376).

En el escenario de graves carencias habitacionales y de demandas de condiciones mínimas de habitabilidad e higiene como las que proliferaban en el mundo urbano del país, surgió la Ley de Habitaciones Obreras de 1906 en Chile, legislación novedosa en cuanto sería precursora en abordar estos problemas y pionera en el contexto latinoamericano. Las primeras iniciativas legales en enfrentar este tema de forma específica habían sido la ley belga de 1889 y la inglesa de 1890, en las que se basaría la chilena para su elaboración. Esta ley fue coetánea a varias similares que surgieron en Europa, como en el caso de Italia en 1903 o la Ley de Casas Baratas de España, de 1911 (Hidalgo, 2000).

Firmada durante el gobierno de Germán Riesco, la Ley de Habitaciones Obreras fue la primera legislación de carácter social relativa a la vivienda social en Chile. A través de ella se estableció como modelo de gestión la generación de los Consejos Departamentales de Habitaciones para Obreros, que funcionarían en las principales ciudades del país a cargo de velar por el cumplimiento de los objetivos del texto: construir, higienizar y normalizar la vivienda popular (Silva, 1997, p. 12).

En un momento de la historia en que las grandes ciudades crecían a un ritmo exponencial extendiéndose como manchas de aceite, merece especial atención una población limitada topográfica, espacial y materialmente, como la de Valparaíso, lo que hace de este caso un ejemplo de referencia. Su importante papel económico en el país, su ubicación y configuración como ciudad-puerto, su alta concentración social a fines del siglo XIx y su singularidad topográfica, serán el argumento que nos lleve a plantearnos cómo se aplicó esta ley y qué resultados obtuvo. Si bien su aplicación en Santiago ha sido estudiada en diversas investigaciones y artículos que caracterizan históricamente la destrucción de numerosas habitaciones insalubres y la construcción de cités en la capital, el caso de Valparaíso ha permanecido ignorado hasta la fecha. La complejidad urbana y social que encerraba la ciudad-puerto en el momento en que surgió esta ley, tras haber sufrido un devastador terremoto e 
incendio (Rodríguez \& Gajardo, 1906, p. 41), hace si cabe más acuciante la necesidad de profundizar en su estudio. Si a todo ello unimos la carencia o parcialidad de fuentes documentales sobre el periodo de tiempo comprendido entre la segunda mitad del siglo xix y el comienzo del siglo xx en Valparaíso, entendemos el porqué de estudiar a fondo las existentes.

Esta investigación analiza histórica y urbanísticamente el impacto que la Ley de Habitaciones Obreras de 1906 tuvo en Valparaíso, las transformaciones que generó en la ciudad y las consecuencias de estas. Unido a ello, el artículo expone las causas por las que la citada legislación no obtuvo los objetivos deseados. En este sentido, estudia la repercusión de las tres funciones principales de esta ley: la nueva construcción generada; el proceso de higienización de las construcciones existentes, materializado tanto en rehabilitación como en demolición; y la normalización que sentará las bases de unas nuevas viviendas, higiénicas y baratas.

\section{Contexto urbano y social de Valparaíso a finales del siglo xIx}

La ciudad de Valparaíso es uno de los asentamientos urbanos más antiguos de Chile. Su ubicación, así como su relación con la costa, han ido conformando una identidad local basada en la relación de la ciudad con el puerto y en un entorno geográfico característico, distinguiéndose claramente la bahía, como zona marítima; el plan, como la zona plana de la ciudad; y los cerros. Desde su origen ha vivido de la actividad portuaria, vinculando así todo su desarrollo urbano al componente globalizador que encierra este tipo de economía. Sus condiciones topográficas específicas y los contextos de modernidad que vieron su desarrollo, han condicionado la fisionomía de la ciudad. Al respecto, Miriam Waisberg (1999) señala que "Valparaíso construye su identidad acuñando características arquitectónicas condicionadas por factores geográficos y sociales insoslayables" (p. 153).

El crecimiento de la ciudad se ha estructurado a lo largo del tiempo a partir de las características naturales de su emplazamiento. La arquitectura se adaptó a las condiciones naturales del sitio, mezclándose con las construcciones europeas de corte victoriano, herencia de los inmigrantes británicos, alemanes o franceses que llegaron a sus costas durante el siglo xix (Sánchez \& Morales, 2009, p. 91). Valparaíso se configuró como centro de la economía del país, con el puerto y la actividad mercantil en torno a él como los principales agentes de desarrollo. Los bancos, las compañías navieras y las exportadoras fueron muy pronto las aglutinadoras de todo el capital económico de la zona. Por otro lado, y debido al auge comercial, desde mediados del siglo xix hasta la primera mitad del siglo xx, Valparaíso concentró la mayoría de las sedes de las nuevas sociedades mineras e industriales, oficinas de ferrocarriles, compañías mercantiles y aseguradoras, y acogió, por ende, una elite social vinculada a ellas (Lorenzo, 2012, p. 14). La ciudad llegó a ser una ventana al exterior, importando tendencias, modas y mercancías. Y junto con ello, el auge comercial originado en ese momento por el incremento de las exportaciones y el desarrollo minero y agrícola, dio lugar a un clima de atracción social y de movimientos migratorios del campo a la ciudad, situación por la cual Valparaíso pasó de tener 52.413 habitantes en 1854 a 193.205 en 1930 (Hurtado, 1966, p. 168). 
Valparaíso fue desde "la residencia favorita de los consignatarios y el centro del mundo de los negocios”, según dice Jacqueline Garreaud (1984), hasta un lugar de asentamiento para una población empobrecida que aumentaba de año en año (p. 162). Urbina subraya que la atracción de inmigrantes se vio favorecida por la alta concentración de estos grupos sociales en los mismos espacios urbanos, hecho que desarrolló un contexto de familiaridad, fraternidad, solidaridad e idealización de las pésimas condiciones habitacionales de Valparaíso. Esta podría ser la explicación historiográfica del auge del proceso migratorio del campo a esa ciudad, a pesar de las duras condiciones que ofrecía (Urbina, 2002, p. 77). El incremento desproporcionado del sector popular pobre cambió la fisonomía de la ciudad-puerto. Por un lado, dado el origen mayoritariamente rural de esta inmigración, se fue configurando una ciudad con una arquitectura basada en tipologías provenientes del campo, que -tal como se muestra en algunas imágenes- se basaban en viviendas realizadas en adobe secado al sol y blanqueado con cal, techos de paja y hojas de palma o, en los mejores casos, de teja. Todas ellas eran de una sola planta, por el temor a los posibles terremotos. En este paisaje urbano y contexto social tan particular, la ciudad creció hacia los cerros que rodean la bahía, con construcciones erigidas sobre sus abruptas laderas y que se encaramaban por las quebradas, dando lugar a una morfología característica y exclusiva de Valparaíso.

El momento de prosperidad que vivió la ciudad por esos años se vio interrumpido por una serie de acontecimientos que cambiaron el devenir de la ciudad: en primer lugar, el terremoto de 1906, que la destruyó en gran parte, afectando sobre todo al sector del Almendral (el plan). En segundo lugar, la apertura del canal de Panamá en 1914, que supuso un duro revés para continuar el sostenido auge y desarrollo del puerto; el tráfico marítimo disminuyó, provocando un decrecimiento de la actividad económica y financiera de la ciudad. Por último, la crisis económica de 1929 cedió paso a la emigración de las industrias hacia Santiago, dando inicio a un periodo de depresión que ha sido muy difícil de revertir y el cual persiste hoy día (Urbina, 1999, p. 432).

Mientras que en Santiago y en otras grandes ciudades los nuevos asentamientos más pobres y populares se fueron ubicando en las nuevas periferias, siguiendo un modelo concéntrico de crecimiento (Capel, 2002, p. 378), en Valparaíso estas nuevas periferias serán los cerros (Puentes, 2013).

La pobreza social materializada en el ejercicio de la autoconstrucción dio lugar a diversas tipologías habitacionales, ya no originadas en las construcciones rurales. Cuartos redondos ${ }^{1}$, ranchos y conventillos se unieron a unas anárquicas arquitecturas en los cerros, que llevaron a Valparaíso a un dramático final del siglo XIX (figura 1).

A los fenómenos de la tugurización y el hacinamiento les siguieron las lógicas lacras de falta de salubridad e higiene. La acumulación de suciedad en las quebradas, la estrechez de los escasos espacios de ventilación, la humedad e inundaciones

1 Tipología caracterizada por un único espacio habitable, sin patio ni pasillo comunitario. Este único espacio era aprovechado para todas las tareas domésticas, tales como lavar, cocinar, etcétera, y su única apertura con el exterior era a través de la puerta. La gran diferencia con los cuartos de los conventillos es que estos daban a un espacio común, bien un patio o un pasillo. 
provocadas por los temporales y la carencia de agua potable limpia fueron el caldo de cultivo perfecto para las numerosas infecciones que no tardarían en llegar (Molina, 2008, p. 205). Esta situación se transformó en una constante. Es refiriéndose a ella que el Consejo Departamental de Higiene señalaba en 1893: "Por las inundaciones ocasionadas por las últimas lluvias y los peligros de aparición de alguna epidemia, se acordó indicar la necesidad de prohibir que se habiten las casas, conventillos y cuartos que fueron inundados. Todos ellos han quedado insalubres e inhabitables"2.

FIGURA I | Autoconstrucciones en la quebrada Elías, Valparaíso, 1892

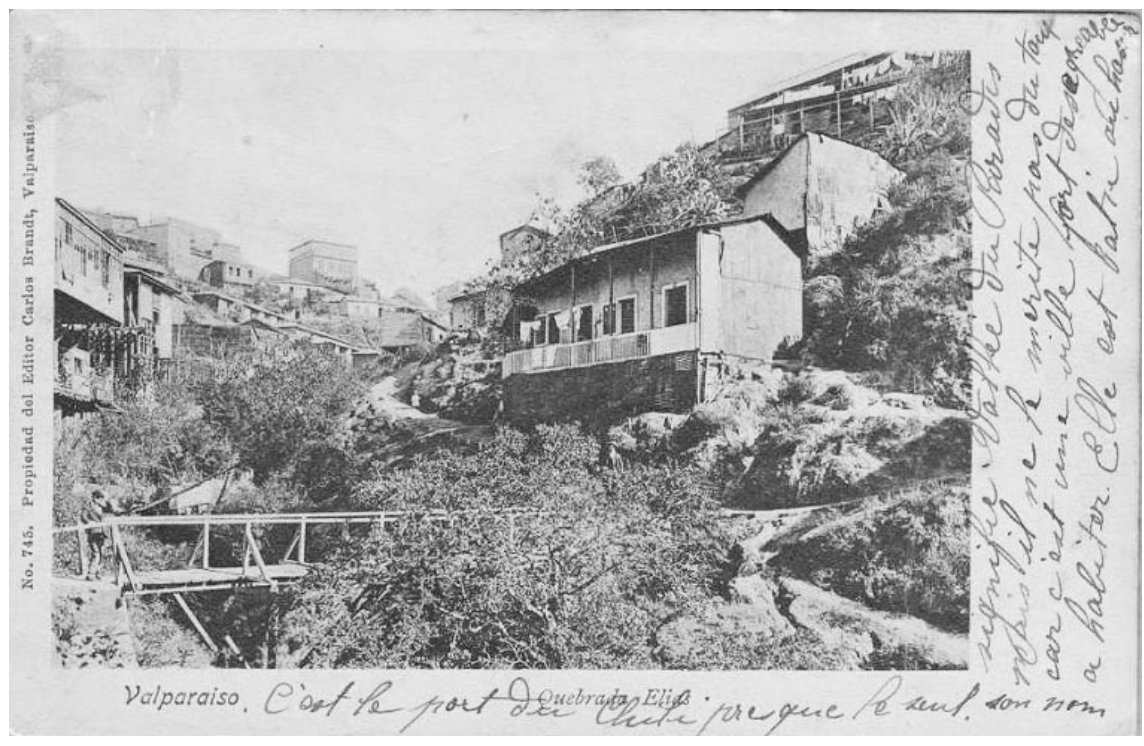

FUENTE FORO AMIGOS DE VALPARAÍSO

La falta de higiene rápidamente dio origen a una creciente alarma social, alimentada en cierto modo por la aparición de construcciones pobres entre las zonas de las elites sociales. Las carencias de servicios básicos, como agua potable y evacuación de residuos orgánicos, agravaron la situación. "Valparaíso padeció los problemas de ciudades mucho mayores, y requería ciertos servicios urbanos -por ejemplo, policía, alumbrado, transporte, pavimentos- más allá de lo que las frías cifras de población lo indican, y antes que otras ciudades de semejante tamaño" (Martland, 2002, p. 70). A este respecto, Mannheim, como director de Obras Públicas de la Municipalidad de Valparaíso, escribió al intendente Echaurren informando de la precariedad higiénica de la ciudad en ese momento, en parte debida a sus construcciones precarias y a un sistema de alcantarillado y abastecimiento deficientes. Le advertía "que los métodos que se emplean al presente para las evacuaciones de las casas son imperfectos; que no llenan las necesidades de todas sino de muy pocas; que son altamente 
anti-higiénicos, y por consiguiente sus vicios se deben en gran parte el mal estado sanitario de este pueblo" (Mannheim, 1876, p. 15).

Una epidemia de viruela en 1886, dos de cólera en 1887 y en 1892, otra de tifus en 1895 (Flores, 1993), etcétera, fueron acentuando en la opinión pública una imagen de insalubridad causada por la dejadez de vida en las construcciones y zonas pobres de la ciudad, de la que se hacían eco continuamente los medios de la época. La revista $Z i g-Z a g$ señalaba que estas arquitecturas eran "focos permanentes de infección y contagio para todas las enfermedades que llegan al país (...) y no es raro que en tales condiciones tengamos aquí una mortalidad aterradora por sus cifras totales, sobre todo, entre los niños del bajo pueblo" 3 . El conventillo se convirtió muy pronto en sinónimo de suciedad y enfermedad. "El conventillo o la mazmorra que habita, lejos de atraerlo como un sitio de descanso y comodidad, empuja a la cantina y a los vicios, pues no encuentra en su casa sino un foco de pestilencia, de estrechez inverosímil, de miseria y abandono" ${ }^{4}$. Esta realidad sería vista como la causante de todos los males del momento (Urbina, 2002, p. 212). Pero si la elite social proyectaba sobre estas construcciones todo un imaginario colectivo de miseria y pobreza, fueron sus habitantes mismos los que comenzaron a verlas como el resultado de un proceso de injusticia social. El aumento progresivo de la violencia afincada en estas zonas de la ciudad fue gestando un malestar que, con la justificación de una demanda relativa a la jornada de trabajo y a una mejora de los ingresos, derivó en la huelga portuaria del 13 de mayo de 1903. "En la madrugada numerosos grupos de gente pobre empezaron a bajar desde los cerros al centro de la ciudad respondiendo a un soterrado llamado de los huelguistas (...). A partir de las 9 de la mañana comenzaron a sucederse incidentes que irían in crescendo" (Grez, 2004, p. 88). El Estado reaccionó con mano dura en contra de los obreros. La huelga de los trabajadores portuarios arrojó un saldo de cincuenta muertos y doscientos heridos. Las protestas derivaron en un estallido social, fenómeno que se comenzó a dar a principios del siglo xx y que puso en evidencia la precariedad de las condiciones de vida y trabajo de la gran mayoría de los chilenos y la poca voluntad por parte del gobierno para dar solución a las legítimas demandas de los trabajadores. En este contexto social tuvo su origen la referida Ley 1.838 de Habitaciones Obreras de 1906.

\section{Iniciativas previas en Valparaíso}

Previo a la aparición de la Ley de Habitaciones Obreras de 1906, a finales del siglo XIX, Valparaíso contaba con una serie de normativas de carácter municipal que, como veremos, continuarían en vigencia hasta bien entrado el siglo xx. Estas normativas y decretos tenían como único objetivo la regularización de las construcciones precarias y, por tanto, el control higiénico de las zonas de la ciudad donde se asentaban. Este tipo de legislación de carácter local se dio simultáneamente en la mayoría de las grandes ciudades chilenas, como en el caso de Santiago (Hidalgo, 2002).

3 Zig-Zag, 20(1001), 26 de abril de 1929.

4 Revista de la Habitación (Órgano del Consejo Superior y de los Consejos Departamentales de Habitaciones Obreras), 1(1), Santiago, diciembre, 1920, p. 17. 


\section{El Decreto sobre Higiene de Conventillos de $1870^{5}$}

Firmada por Francisco Echaurren, esta norma municipal tuvo su origen en la demanda de numerosos vecinos que denunciaban la acumulación de basuras y el vertido de aguas sucias. Apelando a la salubridad y aseo de los conventillos, el decreto obligaba a sus dueños a diversas medidas de limpieza, bajo pena de prisión o multa si se llegara a su incumplimiento. El breve articulado de este decreto muestra una imagen concreta de estas construcciones y de su estado de dejadez. La acumulación de basuras, restos de construcciones y materiales aparece como una tónica común en las sucesivas denuncias interpuestas.

Junto a las medidas de carácter superficial y de limpieza, el decreto obligaba a la instalación de los servicios mínimos, como pozos para letrinas, así como a la determinación de un lugar cerrado y ventilado en el que pudieran ubicarse. El sistema de retirada de restos orgánicos se basaba en la ubicación de un colector que estaba pensado para que diariamente fueran recogidos. La realidad del uso es que podían pasar varios días e incluso semanas sin recibir la asistencia municipal. Esto daba lugar a que los vecinos utilizasen las quebradas entre los cerros para tirar las materias fecales, siendo estas un nuevo foco de insalubridad (Urbina, 2012, p. 148).

\section{Ley de Transformación de Valparaíso de 1876}

Esta ley, promulgada el 6 de diciembre de 1876, que normaba los trazados de calles y avenidas, regulaba la construcción de edificios públicos y privados y el emplazamiento de barrios e industrias, supuso un intento de cambio de morfología y estructura urbana de la ciudad. Abanderada por Francisco Echaurren, pretendía centrar en el plan prácticamente toda la intervención mediante la dotación de nuevos equipamientos, ensanches y pavimentación de las calles. Era de carácter urbano y no incluía especificaciones sobre la articulación de los conventillos. De hecho, se sustentaba en el concepto europeo de ensanches, flujos, plazas y espacios verdes. Para poder ejecutarla, se describían las características que debía tener cada una de las calles, tanto en la proyección de las nuevas como en la modificación de las existentes. Buscaba cierto criterio de unidad entre el plan y los cerros, generando viales que se prolongaran de un lugar a otro y cosieran este borde urbano.

El texto prohibía los trazados urbanos con calles sin salida, intentando así generar nuevos flujos en la ciudad que evitaran los puntos de hacinamiento antihigiénico. Articulaba también un sistema de viales, los cuales, en función del ancho, ocupaban un papel principal (actual avenidas Argentina y Victoria, Independencia, etcétera) o secundario en el trazado de la ciudad. En torno a estos grandes ejes se permitiría la construcción de edificios en altura, mientras que en las proximidades de los cerros, un máximo de dos alturas era el límite establecido.

Con respecto a las construcciones, la norma determinaba qué materiales se podían utilizar. Quedaba prohibido el uso de materiales ligeros como calaminas, cartones o chapas y solamente se permitía el uso de madera, adobe o cemento para la construcción de las estructuras. 
Junto a estas normativas sobre el diseño de la ciudad había otras determinaciones de carácter administrativo, como los procedimientos para la obtención de permisos de obra, fuesen del tipo que fuesen: edificios, conventillos o fábricas.

\section{La Ordenanza sobre Higiene de Conventillos de 1892}

La ordenanza sobre higiene de los conventillos ${ }^{6}$, de 1892, destinada específicamente a obligar a la instalación de saneamiento, incluía tres novedades relevantes respecto de la anterior. En primer lugar, indicaba que la Municipalidad se haría cargo de los gastos de aquellos conventillos en los que sus propietarios no dispusieran de solvencia suficiente, permitiéndoles reembolsar posteriormente, en cuotas, el dinero recibido. En segundo lugar, la Municipalidad podía declarar inhabitables algunos conventillos y prohibir su uso. Y en tercer lugar, incluía una referencia al Consejo Superior de Higiene Pública, constituido en este contexto para asesorar sobre la salubridad y establecer las condiciones básicas para la habitabilidad de las viviendas. Cuando surgió esta ordenanza en 1892, ya se habían dado algunos de los casos más dramáticos de epidemias, y la sociedad porteña había relacionado el origen de estas enfermedades con la precariedad higiénica de los conventillos. La ordenanza, por tanto, se constituyó en un nuevo intento de acotar el contexto de sucesivos estados de precariedad habitacional. La publicación de una nueva norma tan solo veinte años después del decreto de 1870 , evidencia que este no había surtido el efecto deseado. Si hablaba de consultar y consensuar cualquier medida y, en caso de no cumplirla, aplicar una sanción económica, según el nuevo decreto se aplicarían, junto a posibles penas pecuniarias, otras como la demolición y la declaración de inhabitabilidad.

La ordenanza de 1892 se ordena en doce artículos divididos en tres bloques. El primero está dedicado únicamente a normar el servicio de recogida de aguas sucias, letrinas y zonas de depósitos de basuras. Tras la experiencia del decreto anterior, se volvía a insistir en el uso de depósitos y en su cambio diario. Un segundo bloque estaba dedicado nuevamente al pavimentado de los patios, calles, callejones y espacios públicos, para evitar la acumulación de aguas. También intentaba ordenar los enlosados del interior de las habitaciones, obligando a la colocación de un suelo, bien de madera o bien de ladrillo. De forma más flexible, deja a elección de los propietarios el uso de cal en el interior y exterior de la vivienda. El último grupo de artículos volvía a versar sobre los pozos y depósitos de acumulación de aguas residuales, regulándolos en función del ambiente que generan y la escasez de ventilación de los espacios.

\section{Otros decretos}

Junto con los anteriores, hubo otra serie de decretos municipales de menor relevancia, en los que se retomaban cuestiones básicas antes descritas: evacuación de residuos, estado de las zonas comunes entre conventillos y advertencia sobre los riesgos de salubridad. Así, por ejemplo, el Decreto 12 de 7 de enero de $1903^{7}$ de los Conventillos, 15 de septiembre de 1892.

7 Amv. Documentos de la Ilustre Municipalidad de Valparaíso, vol. 24. 7 de enero de 1903. 
incluía una demanda de agua potable de calidad y prohibía la extracción de agua de los pozos, dada su proximidad con los pozos negros. Igual ocurrió con el Decreto 439 de 23 de marzo de $1902^{8}$, en el que, tras una denuncia, se exigía a unos vecinos extraer escombros y basuras de sus habitaciones y pavimentar los suelos. Todos estos decretos ad casum, surgidos de demandas puntuales o grupales, incidirán miméticamente en las mismas demandas.

\section{La aplicación de la Ley de Habitaciones Obreras de 1906 en Valparaíso}

En 1906 tuvo lugar la primera iniciativa estatal, al nivel de intervención nacional, para dar una respuesta global a la preocupación por el tema habitacional, a través de la promulgación de la Ley 1.838 sobre Habitaciones Obreras. Esta ley contendrá numerosas novedades, en comparación con los aparatos legislativos municipales analizados anteriormente. Si bien los objetivos eran los mismos, será la forma de alcanzarlos lo que caracterizará este nuevo corpus jurídico, que tendrá un periodo de vigencia limitado hasta 1925. A partir de este momento, se sucederán leyes que garantizan la obligatoriedad en la educación primaria, el ámbito sanitario, laboral, etcétera; en definitiva, a partir de ella se irá fraguando el Estado del bienestar chileno.

El concepto de vivienda higiénica que promovía la Ley 1.838 recogía de forma explícita el modelo idealizado centroeuropeo y debatido en los Congresos de Casas Baratas (figura 2). Quedaba perfectamente definido por Zenón Torrealba (1920): "Su hogar entonces debe tener un patio interior donde instalar un baño, un columpio, una barra, un trapecio. Apenas llegue a tener fuerzas y capacidad para el trabajo, necesitará un dormitorio con suficiente luz y ventilación, una salita de lectura, etc., donde reponer su cuerpo y su espíritu del desgaste producido en la faena diaria" (p. 16).

A través de la aplicación de una serie de beneficios, la Ley de Habitaciones Obreras buscaba reformar y cambiar el devenir de insalubridad acaecido hasta este momento. En primer lugar, planteaba una exención fiscal a todas las viviendas, individuales o colectivas, que fueran declaradas higiénicas, con el objetivo de animar a los vecinos a mantener limpias sus casas. Seguidamente, por un precio simbólico, otorgaba el derecho de consumir agua potable en una media de 100 litros diarios a los habitantes de las casas. También contemplaba la pavimentación gratuita de calles y aceras por parte de la Municipalidad, junto al servicio de alumbrado público. Por último, preveía la instalación de alcantarillados donde no los hubiera. Favorecía con exenciones de impuestos a las empresas que emprendieran la construcción de viviendas baratas. Estas medidas llevaron a que la Ley 1.838 tuviera un impacto notable en las ciudades chilenas, pero, sobre todo, en el número de viviendas declaradas insalubres y demolidas, que llegó a ser muy superior al de nuevas construcciones (Hidalgo, 2001). La aplicación no fue homogénea en todo el país. En Santiago comenzó a ejecutarse desde su promulgación y concentró tempranamente las iniciativas de la edificación, tanto las promovidas por organizaciones obreras como las impulsadas por sectores privados. En otros lugares, como, por ejemplo, Talca o Chillán, en 1920

Amv. Documentos de la Ilustre Municipalidad de Valparaíso, vol. 11. 23 de marzo de 1902. 
aún no se había puesto en práctica. Y hubo ciudades, como Valdivia, que declararon una escasa acción "porque con ella es muy temible el provocar una crisis muy aguda de la habitación”" Valparaíso fue un claro ejemplo de este proceso heterogéneo.

FIgURA 2 Proyecto de cité para obreros, encargado por Bernardo Moltedo en el cerro Larraín

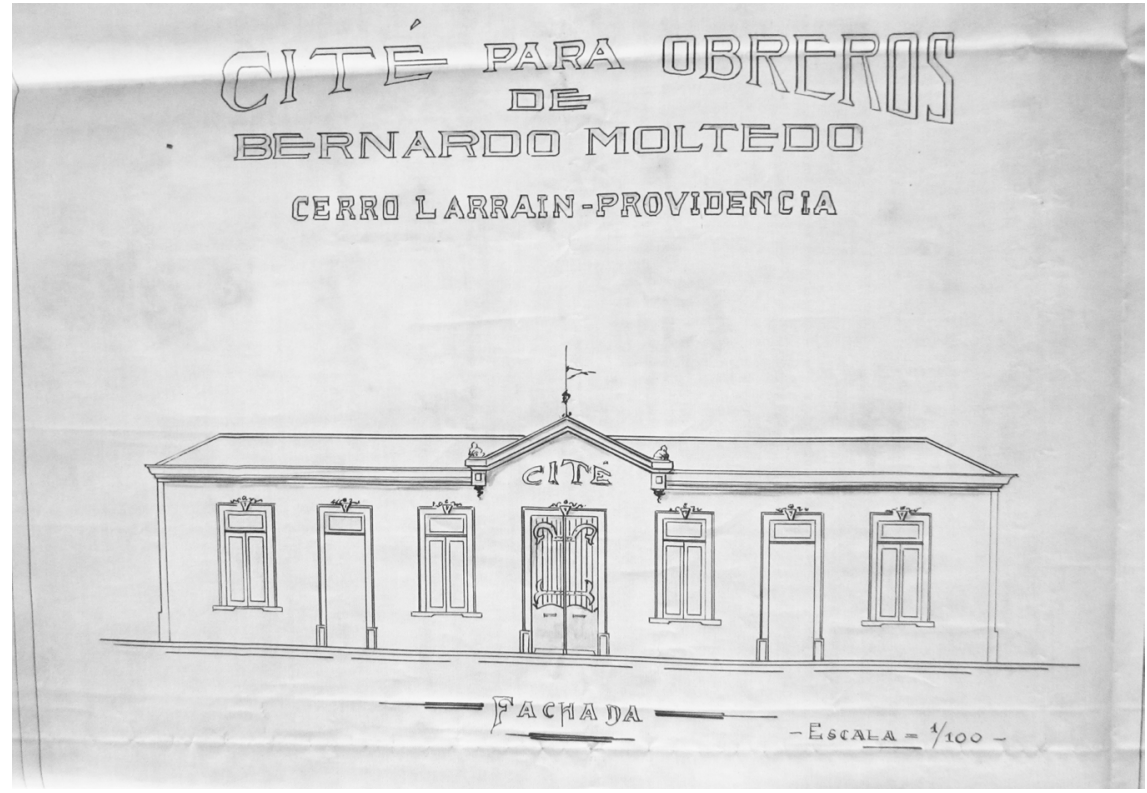

FUENTE ARCHIVO MUNICIPAL DE VALPARAÍSO (AMV). EDIFICACIÓN. EXPTE. N. ${ }^{\circ} 746$ DE I9I 4

A las novedades descritas anteriormente, esta ley añadía una definición explícita de "insalubridad", originada en el contexto higienista de la época, y promovía la creación de los denominados Consejos de Habitaciones, que se ubicarían en las principales ciudades y estarían coordinados a través de un Consejo Superior, que funcionaba en Santiago. Así surgió el Consejo Departamental de Habitaciones Obreras de Valparaíso, cuyos objetivos fundamentales eran la realización de un catastro a partir del cual poder declarar como insalubres o inhabitables las habitaciones que no cumpliesen con los mínimos exigidos y favorecer la construcción de habitaciones higiénicas y baratas, ya sea mediante la construcción directa o el fomento a las sociedades y empresas.

\section{El Consejo Departamental de Habitaciones Obreras de Valparaíso}

El primero de estos consejos estaba integrado por el intendente Aníbal Pinto Cruz, como presidente, mientras que Ángel Guarello ocupaba la vicepresidencia. Los consejeros nombrados fueron Enrique Dublé, Carlos Artigas, Manuel Muñoz Cornejo,

9 Actas de Consejos Departamentales. Revista de la Habitación (Órgano del Consejo Superior y de los Consejos Departamentales de Habitaciones Obreras), 1(1), Santiago, 1920, p. 108. 
el presbítero Francisco Javier de la Fuente, los médicos Cornelio Durán y Manuel J. Olivares. El secretario sería Jorge Prieto Castro, y Manuel Vásquez Rojas ocuparía el cargo de ingeniero, necesario según la citada ley. La sede estaba en el No 143 de la calle Serrano y permanecía abierta para la atención al público todos los días, mañana y tarde.

El Consejo no empezó a funcionar y asumir sus competencias sino hasta $1912^{10}$. Desde el año de aprobación de la ley hasta ese momento se sucedería una serie de decretos de carácter local destinados a solucionar el problema de la habitación tal como se había venido haciendo hasta ese momento. Así lo muestran los numerosos y sucesivos edictos que año tras año la Municipalidad aprobaba para intentar poner remedio a los serios problemas de salubridad que asolaban la ciudad. Ejemplo de ello es el Decreto 149 de 7 de febrero de $1907^{11}$, en el que se describe cómo han de construirse y ubicarse los lugares donde depositar la basura, o el Decreto 833 de 12 de octubre de $1906^{12}$, en el que se insta al saneamiento de los conventillos y al uso de cal, bajo pena económica si no se cumpliera. Entre todos ellos, merece especial mención el Decreto 12 de 7 de enero de $1907^{13}$. En él se recoge de forma sintética todo el problema de la habitación precaria: ubicación en lugares ventilados; uso de agua potable limpia y no de los pozos; evacuación de restos orgánicos; retirada y no acumulación de basura, etcétera. En definitiva, una legislación paralela a la estatal.

El Consejo Departamental de Habitaciones de Valparaíso asumió la triple función de construir habitaciones según los dictados de las nuevas ordenanzas derivadas de la ley; higienizar las existentes, rehabilitando y demoliendo lo que estimara oportuno; y reglar y normalizar la vivienda popular. Para ello, su primer objetivo fue la elaboración de inventarios sobre el estado de las construcciones, así como su salubridad. De estos inventarios se derivaría el procedimiento que debía aplicarse en cada una de ellas. Desde 1912, ańo en el que dio comienzo la actividad del Consejo Departamental en Valparaíso, hasta el 1 de noviembre de 1920, cuando se realizó el primer análisis, publicado en la Revista de la Habitación, se habían demolido 1.122 piezas de 114 conventillos; se habían reparado 404 piezas de 33 conventillos y se habían realizado 209 juicios $^{14}$. Como se puede observar, fue muy superior el número de demoliciones al de reparaciones. La eliminación de estos cuartos supuso un aumento de la presión social y de demanda de techo, con el consiguiente incremento del precio de los cuartos existentes. La mayor parte de los vecinos desalojados de los cuartos eliminados subía a los cerros, donde ocuparían nuevas áreas mediante la autoconstrucción. La prensa de la época se hizo eco de esta subida exponencial de la demanda habitacional. "La opinión pública, viene alzándose en Valparaíso un clamor angustiado y constante. ¡No hay casas para vivir!, exclaman los pobres”15.

Revista de la Habitación (Órgano del Consejo Superior y de los Consejos Departamentales de Habitaciones Obreras), 1(3), Santiago, diciembre, 1920, p. 180.

11 Amv. Documentos de la Ilustre Municipalidad de Valparaíso, vol. 24. 7 de febrero de 1907.

12 Amv. Documentos de la Ilustre Municipalidad de Valparaíso, vol. 21.12 de octubre de 1906.

13 Amv. Documentos de la Ilustre Municipalidad de Valparaíso, vol. 24. 7 de enero de 1907.

14 Actas de Consejos Departamentales. Revista de la Habitación (Órgano del Consejo Superior y de los Consejos Departamentales de Habitaciones Obreras), 1(1), Santiago, octubre, 1920, p. 19.

15 La Unión, Valparaíso, 20 de noviembre de 1919. 
En Valparaíso, a diferencia de Santiago, no se desarrollaron muestras importantes de nuevas construcciones basadas en los modelos higienistas que impulsaba la ley en este periodo. "Hemos dicho que, desde hace años, no se levantan regulares edificios para los pobres y que los pocos que hay están semi-destruidos por la acción del tiempo, en cambio ha aumentado enormemente la población" ${ }^{16}$. La aplicación de la ley en Valparaíso fue cuestionada por el propio gobierno de la Nación. A este respecto, se produjo un debate en el Senado el 17 de febrero de 1921, en el que el ministro de Industria y Obras Públicas, Torrealba, subrayó que "en Valparaíso, donde las habitaciones son más estrechas que en cualquiera otra ciudad, más escasas, más caras, y también bastante insalubres, no se ha hecho inversión alguna, excepto para la compra de algunos terrenos, y se está esperando todavía que haya fondos para iniciar las construcciones" ${ }^{17}$.

Como puede verse, el carácter singular de la geografía porteña también tuvo repercusiones en la aplicación de esta ley. El Consejo Departamental de Valparaíso chocó con el Consejo Superior, tal como muestra la diferencia de criterio sobre la Población Modelo, proyecto que tras obtener el visto bueno en Santiago fue frenado por las reticencias del Consejo local.

Que la habitación de la familia obrera debe estar constituida en un solo plano, cualquiera que sea el número de pisos de que conste la construcción (...). Si el obrero está acostumbrado a habitaciones reducidas, cuando no lo está en piezas redondas, el ideal evidente en el mejoramiento de su casa es el gradual, es decir, de la pieza redonda o conventillo a la cité higiénica y de ésta a la casa propiamente tal, con cierto número de habitaciones y la independencia doméstica que ella significa. (Acta de sesión Departamental de 26 de septiembre de 1919. Archivo Municipal de Valparaíso)

En 1921, ya muy avanzado el periodo de vigencia de la ley, Alberto Mackenna, nuevo presidente del Consejo Superior, llama la atención al presidente del Consejo Departamental de Valparaíso para recordarle cuál es el objetivo de este texto. "La labor principal que hoy día corresponde a ese Consejo es la aplicación estricta de la ley de 20 de febrero de 1906, en orden al saneamiento de las habitaciones obreras anti-higiénicas, las que existen en gran número en esa ciudad y no han sido combatidas como fuera de desear" ${ }^{18}$. Estas disensiones no serán las únicas. En varias ocasiones enviarán desde Santiago a Valparaíso al secretario del Consejo Superior, Ernesto Arteaga, para llevar a cabo un control más directo.

El balance positivo que tuvo la acción higienizadora de los Consejos Departamentales con las numerosas demoliciones de conventillos, contrasta con el efecto negativo de la escasez de nuevas viviendas y su repercusión en los precios de estas. Tal será uno de los puntos fundamentales en la demanda de una nueva ley o la reforma de la anterior. Esta demanda social surtió efecto en 1925 con la aprobación del

16 La Unión, Valparaíso, 8 de enero de 1919.

17 Acta del Senado de 17 de febrero de 1921, Revista de la Habitación (Órgano del Consejo Superior y de los Consejos Departamentales de Habitaciones Obreras), 1(5), Santiago, marzo, 1921, p. 314.

18 Nota al intendente de Valparaíso con motivo del comienzo de su administración. Revista de la Habitación (Órgano del Consejo Superior y de los Consejos Departamentales de Habitaciones Obreras), N.o 4, Santiago, enero, 1921, p. 277. 
Decreto Ley 261, conocido como Ley de Vivienda, donde, reconociendo la subida de los alquileres y el problema que ello suponía para los habitantes de las propiedades insalubres, se planteaba una reducción de un 50 por ciento en los precios de alquiler y una limitación en los precios de las viviendas salubres (Hidalgo, 1999).

La Ley de Habitaciones Obreras de 1906 tuvo sus propias ordenanzas ${ }^{19}$, editadas y publicadas posteriormente en septiembre de ese mismo año, las cuales traducían conceptos en arquitectura: definían los espacios y alturas mínimas, los lugares aptos para la habitabilidad, las condiciones que debían cumplir las instalaciones de abastecimiento y saneamiento, la materialidad, etcétera.

Las áreas de los conventillos en Valparaíso se ubicaban, sobre todo, en la zona de la ladera próxima al plan y fueron extendiéndose hacia lo alto de los cerros. El proceso de transformación y de sustitución debería haber generado en estas zonas las nuevas construcciones higiénicas, pero no fue así. A la etapa de eliminación no le continuó la de construcción (figura 3). Los motivos que originaron esta carencia constructiva estarían determinados por una topografía adversa a construcciones masivas, una escasez aguda de materiales baratos que permitieran construir a precios lógicos para una clase empobrecida, la falta de interés inversor por parte de los propietarios de los terrenos y una fuerte vinculación a la autoconstrucción, respaldada por el alto porcentaje de inmigración rural.

\section{La topografía}

Las ordenanzas derivadas de la ley planteaban unas condiciones mínimas que debía cumplir el terreno para proceder a urbanizar según el criterio higiénico establecido por la normativa, y definían los lugares lógicos para la construcción: se buscaba sitios planos y abiertos a la ventilación. La compleja topografía donde se ubicaban los conventillos porteńos hacía imposible proceder a urbanizar y a insertar un modelo habitacional racionalizado, según prescripción de la Ordenanza 4.980. "La totalidad del terreno que se tiene en esta ciudad no es apropiado para construir habitaciones obreras y para determinar qué partes serían aprovechables, se nombró una comisión que estudió este punto y llegó a establecer que habría manifiesta conveniencia en cambiar la ubicación de un camino vecinal y deslindada la parte reservada para la población proceder a la subasta del resto" ${ }^{20}$. Un lugar tan particular como Valparaíso no podía encajar en un modelo genérico de arquitectura colectiva; demandaba un modelo propio, uno capaz de usar los recursos del lugar y que supiera adaptarse a él. Los cerros de Valparaíso y sus quebradas no podían asumir una arquitectura genérica, por muy higiénica que fuera. La complejidad de la topografía obligaba a propuestas que consideraran no solamente las pendientes de los cerros, sino también lo referente al abastecimiento y a la evacuación de residuos,

19 Ordenanza sobre Habitaciones para Obreros, N. ${ }^{\circ}$ 4.980. Santiago, 17 de septiembre de 1906. En Consejo Superior de Habitaciones Obreras, Asamblea de la Habitación Barata, celebrada en Santiago los días 28, 29 y 30 de septiembre de 1919. Santiago: Imprenta y Litografía La Ilustración, 1920, pp. 344-346.

20 Informe remitido por el Consejo Departamental de Valparaíso al Consejo Superior. Revista de la Habitación (Órgano del Consejo Superior y de los Consejos Departamentales de Habitaciones Obreras), 1(3), Santiago, diciembre, 1920, p. 182. 
aspectos que no podían ser solucionados con un planteamiento común. "Ahora que ya hemos entrado de lleno en los duros meses de invierno, con todo su cortejo de mayores dificultades, de lluvias, de inundaciones, de destrucción, de caída de murallas y casas viejas, ha venido a presentarse en forma mucho más apremiante y sensible aún, que en el buen tiempo, el antiguo problema de la habitación escasa y cara, en Valparaíso" ${ }^{21}$.

FIgURA 3 | Proyecto utópico de cité "palafítico" como intento de adaptación de las arquitecturas higiénicas a los cerros

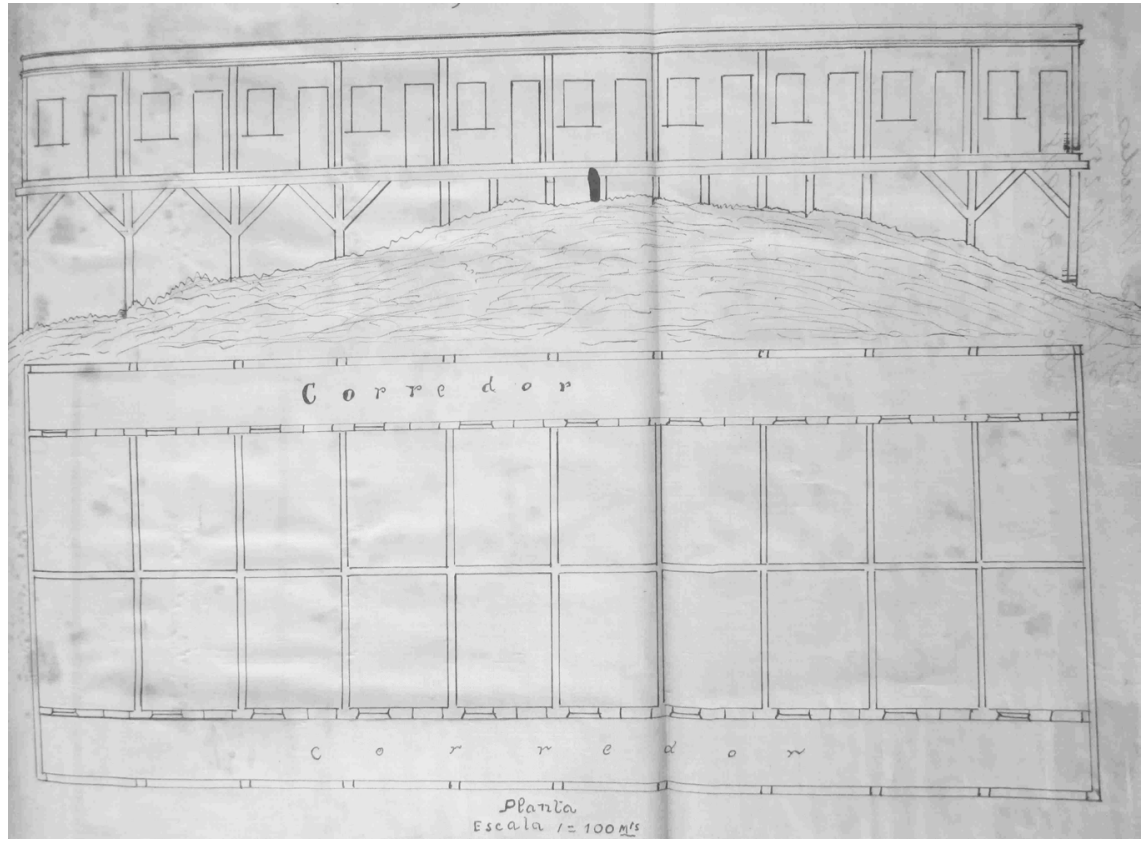

FUENTE ARCHIVO MUNICIPAL DE VALPARAÍSO (AMV). EDIFICACIÓN. EXPTE. No 703 DE I 9 I 5

\section{Escasez de materiales}

Los conventillos que habían sido declarados inhabitables y se demolían no volvían a ser reconstruidos. El uso de materiales que exigían las Ordenanzas, tales como cemento, hormigón, etcétera, no resultaban económicos para construir y que las viviendas continuaran siendo rentables y accesibles para el tipo de población a las que estaban destinadas. Por otro lado, los materiales ligeros seguían siendo utilizados de forma ilegal. La aparición de la Forestal Valparaíso o el uso de pino Oregón, traído hasta el puerto por los lastres de los barcos salitreros, concentraron en la ciudad, de forma permanente, una alta oferta de madera y tableros que era asequible a estas clases empobrecidas. "Debido a la escasez y carestía de los materiales

21 Informe del Consejo Departamental de Valparaíso al Consejo Superior. Revista de la Habitación (Órgano del Consejo Superior y de los Consejos Departamentales de Habitaciones Obreras), 2(18), Santiago, 1922, p. 375. 
de construcción no se edifica actualmente el conventillo que haya sido destruido por inhabitable y no se repara el que está clausurado por insalubre. Esta situación ha contemplado el Consejo para no decidir la demolición sino en casos ineludibles. Es notable, además, la resistencia de los propietarios para cumplir las órdenes que el Consejo les notifica y debe atribuirse esta actitud a las circunstancias aludidas"22. La realidad de la pobreza material hizo que muchas construcciones, aun siendo insalubres, permanecieran en pie al saber el Consejo que, de ser demolidas, dejarían a esas familias sin techo y sin alternativa para tenerlo. Las escasas intervenciones que se hicieron en Valparaíso fueron prácticamente en su totalidad referidas a reconstrucciones y mejoras. Estas también supusieron un serio problema. Por pobres y precarias que fueran las reformas, justificaban un alza en los precios de las habitaciones. "El resultado lógico fué que construyó casas con regulares materiales y con un precio de venta que resulta enormemente alto para los escasos jornales que gana el proletario nacional" (Torrealba, 1920, p. 16). Ante esta evidente irregularidad en la ejecución de la ley, el Consejo Departamental propuso alternativas materiales. Así lo expresaba un informe remitido al Consejo Superior:

La baratura de la madera, que es el principal elemento que se emplea en la construcción de la habitación popular, permitiría a los propietarios de terrenos eriazos, como existen en gran cantidad en la parte alta, edificarlos a poco costo; a otros les permitiría hacer la demolición de sus casas viejas y construir nuevas, cosa que hoy no pueden verificar por el gasto falto de la debida compensación que ello implica; y a otros, en fin, les permitiría iniciar mejoras y reformas a poco gasto en muchas viviendas que lo reclaman imperiosamente ${ }^{23}$.

\section{Autoconstrucción}

La procedencia rural de gran parte de la nueva población de Valparaíso favorecía una vinculación directa al ejercicio de la autoconstrucción según modelos locales. Esta forma de construcción, que era prohibida por las Ordenanzas de la Ley, daba como resultado una arquitectura local, un modelo propio. El Consejo Departamental no lo vería mal, pero el Superior nunca lo aprobaría. "En este año nuevamente se confeccionaron planos y presupuestos para la construcción y se pidieron propuestas públicas, las que no fueron abiertas por orden de ese Consejo Superior, el cual indicó que debía estudiarse otro tipo de construcción que los conocidos y que deberían consultar la idea de habitación colectiva o cité higiénica" ${ }^{24}$. El Consejo Departamental era consciente de que el cité higiénico promovido por la ley no se adaptaba a la realidad porteńa.

22 Informe remitido por Ángel Guarello, vicepresidente del Consejo Departamental al Consejo Superior. Revista de la Habitación (Órgano del Consejo Superior y de los Consejos Departamentales de Habitaciones Obreras), 1(3), Santiago, diciembre, 1920, p. 180.

23 Informe del Consejo Departamental de Valparaíso al Consejo Superior. "El problema de la habitación popular. El congreso vecinal”. Revista de la Habitación (Órgano del Consejo Superior y de los Consejos Departamentales de Habitaciones Obreras), No 12, Santiago, octubre, 1921, p. 677.

24 Actas de Consejos Departamentales. Revista de la Habitación (Órgano del Consejo Superior y de los Consejos Departamentales de Habitaciones Obreras), 2(18), Santiago, 1922, p. 402. 
Organizaciones de la Iglesia católica, evidenciando la miseria de estas clases sociales y movidas por planteamientos morales, veían como una necesidad apoyar a estos grupos desfavorecidos con construcciones higiénicas. Si en Santiago fueron numerosos estos proyectos sociales -y se contabiliza que entre 1890 y 1920 se levantaron 180 viviendas en 16 construcciones-, en Valparaíso solo hubo uno, el conjunto de viviendas de la Población Obrera de la Unión (Hidalgo, Errázuriz \& Booth, 2005) (figura 4). A este ejemplo se unieron algunos llevados a cabo posteriormente por sociedades filantrópicas laicas, como el caso del colectivo Favero (construido en 1912 por Giocondo Favero en los cerros Florida y Cordillera), el colectivo Montgolfier (construido en 1910 en el cerro Panteón) o el cité Barón (Ferrada \& Jiménez, 2007, p. 33).

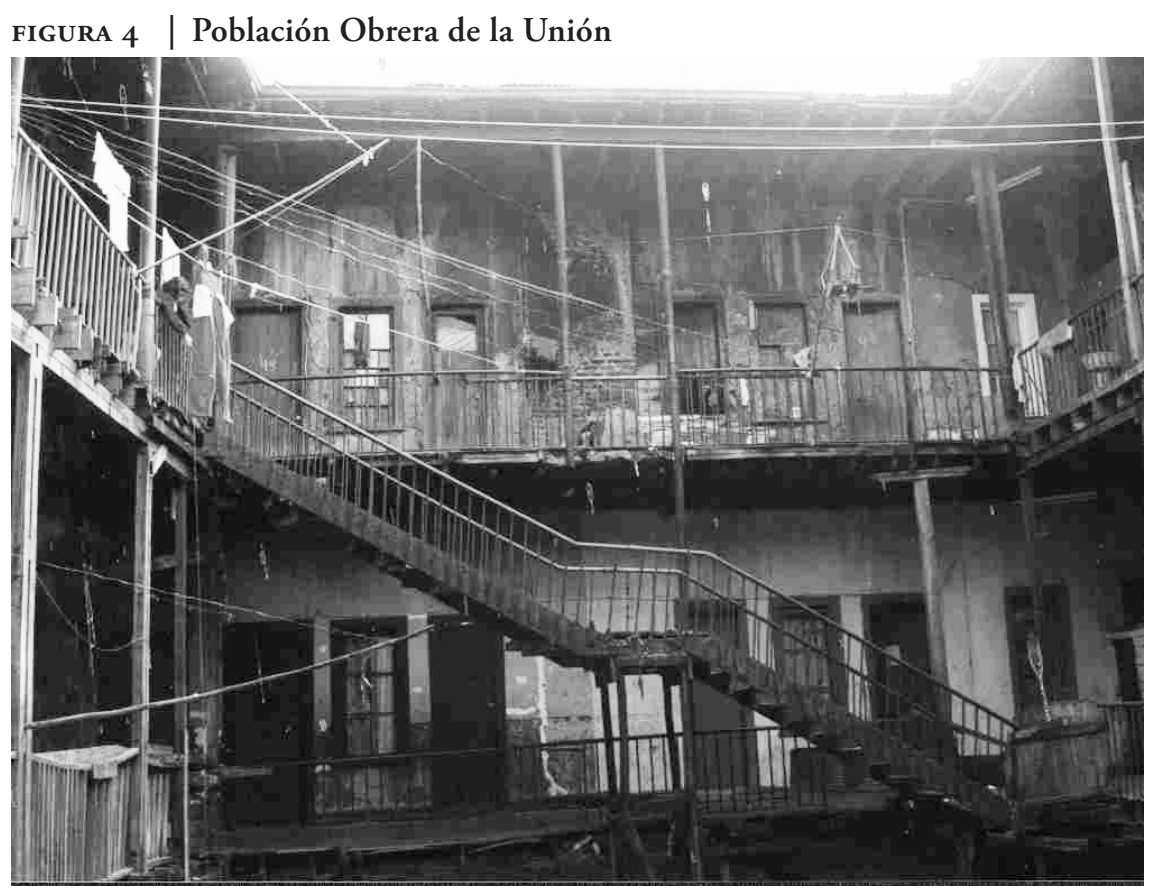

FUENTE IMAGEN CEDIDA POR BORDE URBANO, EQUIPO REDACTOR DEL PROYECTO DE REHABILITACIÓN

Falta de interés de los propietarios y empresas

La ley estableció el marco legal para que empresas privadas se hicieran cargo e invirtieran en la rehabilitación y reconstrucción de las viviendas sociales deterioradas, como una opción de negocio. Las intervenciones, tanto en la reparación como en la construcción de nuevas edificaciones, suponían gastos para los propietarios de los predios y no involucraban mayores ingresos. Así, el Consejo Departamental de Valparaíso hizo saber en varias ocasiones al Consejo Superior que no había mucho interés en emprender tales tareas por parte de los propietarios de las pocas parcelas que cumplían con los requisitos establecidos por las ordenanzas. La indiferencia que mostraban también estaba causada, en cierto modo, por los precios de los materiales 
que permitía la ley para la construcción. "En realidad reditúa mucho más un edificio arrendado cuyo valor de inversión es insignificante que uno que representa valores apreciables invertidos en él. Los beneficios legales no son suficientes para igualar esos rendimientos y sólo consideraciones de orden moral pueden influir en el mejoramiento de las habitaciones" 25 . Esto hizo que Valparaíso pidiera al Consejo Superior permiso para incentivar desde el Municipio la inversión, solicitud que fue desestimada sistemáticamente. "Por este motivo son muy escasas las solicitudes en interés de obtener los beneficios legales y de las que se presentan la gran mayoría es informada desfavorablemente porque los que se presentan consultan más la economía de la construcción que la salubridad de las mismas"26. La otra opción era eliminar directamente las construcciones precarias para alquilar a un precio mayor. Este proceso de sustitución de las edificaciones se dio sobre todo en el plan, y fue el causante de que, procesualmente, la población precaria fuera abandonando la parte plana y comenzara a colmatar los cerros. "El antiguo problema de la habitación popular en Valparaíso, se ha tornado ya ahora en una fiebre aguda, porque las casas se han venido destruyendo por la acción del tiempo, unas, y otras las destruyen sus propios dueños para edificar en su sitio, chalets y cités de mayor precio, precio completamente fuera del alcance de los recursos de modestos empleados y obreros" 27 . En el contexto de epidemias y carencias económicas y materiales en que se vivía en Valparaíso, los promotores no vieron claro que invertir en las viviendas precarias les supusiera una mejoría en la renta, pero sí que acarreaba un gasto que no estaban dispuestos a afrontar. Los inquilinos veían cómo con esta ley se producía una subida en el precio de sus viviendas que no podían asumir, por lo que terminaron coincidiendo con los arrendadores en que preferían quedarse como estaban, porque, por muy mal que fuera, podían tener un techo.

Hacia finales de 1925, la situación en Valparaíso no había cambiado como se esperaba. Con la elaboración del Empadronamiento de la Oficina de Sanidad de la Vivienda, se dio una perfecta imagen de cómo se encontraba la ciudad justo al final de la vigencia de la Ley de Habitación Obreras de 1906. Para la realización de este inventario se dividió el territorio en diferentes zonas sanitarias. Para hacer una descripción física del edificio, el documento se centraba en el número de pisos, el número de habitaciones, el número de casas que lo configuraban, el número de patios y una superficie aproximada de estos y, de forma muy detallada, hacía una descripción de los materiales de construcción utilizados. El inventario distinguía tres modelos: conventillos, casa colectiva y casa separada, de manera que se pudieran agrupar todas las construcciones y, en función de ello, poder actuar. Una vez descrita la realidad física de la construcción, la ficha haría una descripción higiénica que permitiera dar una imagen global de la misma. Este punto era el que determinaba

25 Revista de la Habitación (Órgano del Consejo Superior y de los Consejos Departamentales de Habitaciones Obreras), 1(3), Santiago, diciembre, 1920, p. 183.

26 Informe del Consejo Departamental de Valparaíso al Consejo Superior. Revista de la Habitación (Órgano del Consejo Superior y de los Consejos Departamentales de Habitaciones Obreras), 1(12), Santiago, octubre, 1921, p. 682.

27 Crónica. Revista de la Habitación (Órgano del Consejo Superior y de los Consejos Departamentales de Habitaciones Obreras), 2(12), Santiago, junio, 1922, p. 377. 
si necesitaba ser reformada o demolida. Solamente de la zona IV, tras ser inspeccionadas 544 habitaciones, 157 fueron declaradas insalubres ${ }^{28}$ y prohibida su ocupación hasta reforma o demolición. Tras estas evidentes y ya referidas irregularidades en la aplicación de la ley -como eran el alza de precios de los predios, una fuerte demanda de techo y un débil impacto en la salubridad de las construcciones precarias- se demandó una reforma a este texto legislativo, que vería la luz con el Decreto Ley 261 de 10 de febrero de 1925 y su Reglamento de aplicación, número 137.

\section{Conclusiones}

La Ley de Habitaciones Obreras de 1906 supuso un paradigma con respecto a las leyes y ordenanzas que en materia de habitación obrera se dictaron en Valparaíso a comienzos del siglo xix. Además de la formación del Consejo Departamental, la legislación estableció la creación de un inventario de inmuebles para, en función de él, tomar las decisiones pertinentes. El impacto negativo de esta ley sobre la población estuvo originado por la gran diferencia entre el número de inmuebles eliminados en relación con los construidos. La continua llegada de inmigrantes y la reducción de inmuebles originó una demanda habitacional que acabaría encareciendo los predios existentes.

Las causas del bajo impacto de esta ley fueron varias, pero todas originadas por el mismo motivo: intentar hacer que una ley generalista surtiera efecto en un ámbito tan singular y específico como la realidad porteña de finales del siglo xIx. Enumerando estas causas, encontramos, en primer lugar, la complejidad topográfica de la ciudad, que determinó los pocos ámbitos de la ciudad en los que, según las Ordenanzas, se podían afincar las nuevas construcciones higiénicas. En segundo lugar, hubo que afrontar la escasez de materiales óptimos para el desarrollo de las reformas que requería el decadente estado de los conventillos de Valparaíso. En tercer lugar, el fuerte vínculo de los inmigrantes pobres con la autoconstrucción hizo que, dado que no paraba de llegar nueva población, nunca se terminara de erradicar esta tipología de soluciones habitacionales, que ha perdurado hasta nuestros días. Y en último lugar, nos encontramos con el desinterés de las empresas privadas y promotores por invertir, dado el escaso o nulo margen de beneficio que podían obtener. Esta falta de interés era también manifiesta por parte de los arrendatarios, que veían en la aplicación de la ley una justificada alza en los precios de los alquileres.

El panorama que dejaba la Ley de Habitaciones Obreras tras su vigencia en Valparaíso era el de una ciudad con una fuerte demanda de techo por los múltiples derribos ocasionados; una escasa o casi nula existencia de nueva habitación que cumpliera los requerimientos de habitabilidad exigidos por las demandas higienistas; unos precios de alquiler de cuartos elevados para la población obrera, dada la fuerte demanda; y, lo que era peor, una población afincada en los cerros con fuertes carencias higiénicas no resueltas.

28 Empadronamiento. Oficina de Salubridad de la Vivienda. IV zona sanitaria. Amv. Documentos de la Ilustre Municipalidad de Valparaíso, 1926 (documentación sin catalogar). 
Los resultados de esta legislación tendrían una fuerte repercusión en la fisonomía de la ciudad contemporánea. La opción por la vivienda unifamiliar, la subida a los cerros de la población según trazados autodefinidos y la ausencia de arquitecturas genéricas ajenas al discurso local, permitieron que la singularidad y particularidad arquitectónica de Valparaíso hayan llegado hasta nuestros días.

\section{Referencias bibliográficas}

Capel, H. (2002). La morfología de las ciudades. Barcelona: Serbal.

De Ramón, A. (1990). La población informal. Poblamiento de la periferia de Santiago de Chile. 1920-1970 [Versión electrónica]. EURE, 16(50), 5-17. En http://www.eure.cl/ index.php/eure/article/view/1049

Ferrada, M. \& Jiménez, C. (2007). La primera vivienda social en Valparaíso. Fines siglo XIXinicios siglo xx. En M. J. Castillo \& R. Hidalgo (Eds.), 1906/2006. Cien años de politica de vivienda en Chile (pp. 29-49). Santiago: Facultad de Arquitectura y Diseño, Universidad Nacional Andrés Bello/Instituto de Geografía, Facultad de Historia, Geografía y Ciencia Política, Pontificia Universidad Católica de Chile.

Flores, S. (1993). Las epidemias en Valparaíso. Cuadernos de Historia (Santiago: Universidad de Chile), (12), 16-26.

Garreaud, J. (1984). La formación de un mercado de tránsito. Valparaíso: 1817-1848. Nueva Historia. Revista de Historia de Chile, 3(11), 157-194. En http://www.memoriachilena. $\mathrm{cl} / 602 / \mathrm{w} 3$-article-98582.html

Grez, S. (2004). Los anarquistas y el movimiento obrero. La alborada de la Idea en Chile, 18931915. Santiago: LOM.

Guzmán, L. (1988). Encerrados entre los cerros y el mar: reforma y segregación urbana en Valparaiso: 1870-1880. Tesis para optar al grado de Licenciatura en Historia, Pontificia Universidad Católica de Chile, Santiago.

Hidalgo, R. (1999). La vivienda social en Chile: la acción del Estado en un siglo de planes y programas. [Versión electrónica]. Scripta Nova, Revista Electrónica de Geografía y Ciencias Sociales, 45(1). En http://www.ub.edu/geocrit/sn-45-1.htm

Hidalgo, R. (2000). La política de casas baratas a principios del siglo xx. El caso chileno. [Versión electrónica]. Scripta Nova, Revista Electrónica de Geografía y Ciencias Sociales, (55). En http://www.ub.edu/geocrit/sn-55.htm

Hidalgo, R. (2001). La "cuestión social” y la vivienda en Chile a comienzos del siglo xx. En P. Fraile (Ed.) \& Q. Bonastra (Coord.), Modelar para gobernar: el control de la población y el territorio en Europa y Canadá, una perspectiva histórica (pp. 79-98). Barcelona: Publicacions de la Universitat de Barcelona.

Hidalgo, R. (2002). Vivienda social y espacio urbano en Santiago de Chile. Una mirada retrospectiva a la acción del Estado en las primeras décadas del siglo xx. [Versión electrónica]. EURE, 28(83), 83-106. http://dx.doi.org/10.4067/S025071612002008300006 
Hidalgo, R., Errázuriz, T. \& Booth, R. (2005). Las viviendas de la beneficencia católica en Santiago: instituciones constructoras y efectos urbanos (1890-1920). Historia, 38(2), 327-366. http://dx.doi.org/10.4067/S0717-71942005000200004

Hurtado, C. (1966). Concentración de población y desarrollo económico. El caso chileno. Santiago: Instituto de Economía, Universidad de Chile.

Lorenzo, S. (2012). Ambiente cultural de una ciudad mercantil, Valparaíso: 1830-1930. En B. Estrada (Comp.), Valparaiso, progresos y conflictos de una ciudad puerto (1830-1950) (pp. 13-30). Santiago: Ril editores.

Mannheim, J. B. (1876). La evaluación general de la ciudad de Valparaíso. Valparaíso: Imprenta del "Deber".

Martland, S. (2002). Cuando el gas pasó de moda: la elite de Valparaíso y la tecnología urbana, 1843-1863. [Versión electrónica]. EURE, 28(83), 67-81. http://dx.doi.org/10.4067/ S0250-71612002008300005

Molina, M. (2008). La noción de salud e higiene pública. El caso de la dotación de agua potable en Valparaíso, 1850-1910. Reconstrucción de sus significados. [Versión electrónica]. Archivum, 8(9), 203-221. En https://sites.google.com/site/ archivohistoricopatrimonial/archivum-ao-viii-nmero-9

Puentes, M. (2013). La observación arquitectónica de Valparaíso: su periferia efimera. Valparaíso: Ediciones Universitarias de Valparaíso.

Rodríguez, A. \& Gajardo, C. (1906). La Catástrofe del 16 de agosto de 1906 en la República de Chile. Santiago: Imprenta Barcelona.

Sánchez, A. \& Morales, R. (2009). Las Regiones de Chile (4a ed.). Santiago: Universitaria.

Silva, S. (1997). Estudio análisis de la evolución de la politica habitacional chilena. Informe final. Santiago: Ministerio de Vivienda y Urbanismo.

Torrealba, Z. (1920). La higienización de la habitación obrera. Revista de la Habitación (Órgano del Consejo Superior y de los Consejos Departamentales de Habitaciones Obreras), 1(1), 16-17.

Urbina, R. (1999). Valparaíso: auge y ocaso del viejo "Pancho", 1830-1930. Valparaíso: Puntángeles, Universidad de Playa Ancha.

Urbina, X. (2002). Los conventillos de Valparaíso, 1880-1920. Fisonomía y percepción de una vivienda popular urbana. Valparaíso: Ediciones Universitarias de Valparaíso.

Waisberg, I. M. (1999). El multifacético patrimonio de Valparaíso. En Icomos-Chile (Consejo Internacional de Monumentos y Sitios), Monumentos y sitios de Chile (pp. 447-456). Santiago: Altazor/Universidad Internacional SEK. 

RESEÑAS 